\title{
Screening of Elite Chickpea Germplasm against Ascochyta Blight under Controlled Conditions
}

\section{Javed Anwar Shah ${ }^{1}$, Azhar Iqbal', Muhammad Tariq Mahmood ${ }^{2}$, Muhammad Aslam ${ }^{3}$, Muneer Abbas ${ }^{4}$ and Ilyas Ahmad ${ }^{5 *}$}

${ }^{1}$ Plant Pathology Research Institute, Faisalabad, Pakistan; ${ }^{2}$ Gram Breeding Research Sub-Station, Kallurkot, Pakistan; ${ }^{3}$ Fodder Research Institute, Sargodha, Pakistan; ${ }^{4}$ Arid Zone Research Institute, Bhakkar, Pakistan; ${ }^{5}$ Soil and Water Testing Laboratory for Research, Multan, Pakistan.

Abstract | Ascochyta blight $(A B)$ caused by Ascohyta rabiei is considered as most disastrous and widespread fungal disease of chickpea across the world. Under favorable environmental conditions $A B$ epidemics may cause partial to complete yield loss. Chickpea faces several biotic and abiotic stresses. Among biotic factors chickpea blight is most important factor responsible for drastic decline in productivity. Other disease management approaches are not more efficient and economical except to exploit the host plant resistance mechanism. The present study for screening of 60 elite chickpea lines was carried out for two consecutive years during 2017-18 and 2018-19 under controlled environment at pulses research Institute Faisalabad, Pakistan. Favorable conditions for disease incidence were developed by maintaining the temperature between 15-20 ${ }^{\circ} \mathrm{C}$ and humidity $>70 \%$. Test entries were inoculated equally by spraying fungal suspension during initial flowering and pod filling stages. Observations on disease incidence were recorded by employing 1-9 Disease Rating Scale. Result showed that no line was resistant whereas, only eight chickpea desi lines were found moderately resistant, three lines were tolerant, seventeen were moderately susceptible and the rest thirtytwo lines were found susceptible and highly susceptible. Identified moderately resistant lines (D-17001, D-17005, D-17008, D-17009, D-17011, D-17023, D-17024 and D-17032) may be included in chickpea breeding program for development of $A B$ tolerant chickpea cultivars.

Received | May 22, 2021; Accepted | August 13, 2021; Published | September 22, 2021

*Correspondence | Ilyas Ahmad, Soil and Water Testing Laboratory for Research, Multan, Pakistan; Email: iadasti@gmail.com

Citation | Shah, J.A., A. Iqbal, M.T. Mahmood, M. Aslam, M. Abbas and I. Ahmad. 2021. Screening of elite chickpea germplasm against Ascochyta blight under controlled conditions. Pakistan Journal of Agricultural Research, 34(4): 774-780.

DOI | https://dx.doi.org/10.17582/journal.pjar/2021/34.4.774.780

Keywords | Ascochyta blight, Chickpea, Resistant, Susceptible and highly susceptible

\section{Introduction}

$\mathrm{C}$ hickpea (Cicer arietinum L.) is an important rabi pulsecropbeinggrowninmore than fortycountries across the world (Hirich et al., 2014; Mahmood et al., 2019). It is the mostly grown pulse legume crop in the world after bean and peas. Chickpea (Cicer arietinum L.) is an important food legume crop with an annual global production of about 14.78 million tons (FAOSTAT, 2021). Chickpea is major source of high-quality protein for animals and human beings
(Malik et al., 2011). It also helps in the management of soil fertility through biological nitrogen fixation (Islam et al., 2011). Among the chick pea diseases, Ascochyta blight $(A B)$ results into significant yield loss. Occurrence of this disease has been reported in most of chickpea growing countries of world however more significant yield losses have been reported in India, Pakistan, Australia, Morocco, Spain, Syria, USA, Iran and Canada (Gayacharan et al., 2020). Humid, cool and cloudy climatic conditions are most favorable condition for disease spread (Pande et al., 2005). $A B$ 
epidemics under favorable environmental conditions may cause partial to complete yield loss (Mahmood et al., 2019). Yield losses up to $100 \%$ have been reported in the areas where temperature ranges between 10-25 ${ }^{\circ} \mathrm{C}$ and the relative humidity is more than $60 \%$ during the crop season (Jamil et al., 2010).

Breeding efforts for development of $\mathrm{AB}$ resistant cultivars were initiated on large scale by different research centers during last two decades of twentieth century (Pande et al., 2005). ICRISAT (International Crops Research Institute for Semi-arid Tropics) initiated systematic breeding efforts for exploration of $A B$ resistant germplasm and thousands of chickpea genotypes were screened out for identification of resistant genetic resources (Chongo et al., 2003; Baite et al., 2016). Hybridization attempts for development of $A B$ tolerant genotypes were initiated at ICARDA in 1978 (Islam et al., 2011). ICARDA released and freely shared more than $3000 \mathrm{AB}$ resistant lines between 1981-2002 (Malhotra et al., 2003). In USA, two AB resistant cultivars, Sanford and Dwelly were released in 1990 (Khan et al., 2018).

The fungus can infect all above ground parts of the plant and survives on infested crop residue and seed. The fungus is extremely destructive and significantly affects the yield and quality of chickpea. The yield losses can reach up to $100 \%$ under favorable conditions (Pande et al., 2005). The presence of a sexual phase (Didymella rabiei) in the life cycle of the pathogen leads to high level of variability in aggressiveness within the pathogen populations (Pande et al., 2005). The most efficient strategy to manage this disease is to identify the genetic sources for resistance and to exploit such host plant resistance for development of $A B$ resistant cultivars (Gan et al., 2006; Duzdemir et al., 2014; Gayacharan et al., 2020). Shah et al. (2015) screened 54 elite chickpea advance lines against blight under controlled environmental at NIAB, Faisalabad and concluded that 23 lines were found resistant and 16 as moderately resistant. The entry of new pathotype unable resistant mechanism of chickpea, so there is need of new improved genetic source for $A B$ resistance in Chick pea (Jamil et al., 2010).

Several researchers (Megersa et al., 2017; Rubiales et al., 2018; Mahmood et al., 2019) have emphasized the use of 1-9 disease scale for screening of chickpea germplasm already suggested and proposed by Reddy and Singh (1984) and further elaborated by
(Toker et al.,1999). For this purpose, artificial spore suspensions are prepared, and the screening nurseries are inoculated. Entries are screened out by keeping controlled environmental conditions and the resistant sources are identified for their further exploitation in development of $\mathrm{AB}$ resistant cultivars (Shah et al., 2015).

Screening of germplasm for identification of resistant strains and exploitation of these resistant sources are the key components for development of resistant cultivars (Sarwar et al., 2012). The present study was planned to identify the resistant sources against Ascochyta blight among the elite chickpea advance lines for their further exploitation in development of $\mathrm{AB}$ resistant chickpea cultivars.

\section{Materials and Methods}

Sixty advance chickpea lines were screened out against chickpea blight under controlled environmental conditions at experimental area of Pulses Research Institute, AARI, Faisalabad, Pakistan for two consecutive years during the rabi season of 2017-18 and 2018-19. The experimental material was laid down under augmented design.

\section{Isolation of the pathogen}

Plant samples of Ascochyta blight infected collected from chickpea fields. Infected stems, pods and leaflets presenting clear blight lesions were treated with solution of 5\% sodium hypochloride and dehydrated on uncontaminated filter paper. For fungal growth, this material was plated on $2 \%$ water agar and incubated for 5-7 days at $20^{\circ} \mathrm{C} \pm 2$ with 12 hour light/dark cycle. Fungus colonies were developed after incubation on this media for 1-2 weeks. Similar procedure was adopted by Alam and Strange (1987) who reported that incubation of this material for 1-2 weeks results in fungal colonies with pycnidia.

\section{Multiplication}

For multiplication of fungus, chickpea grains were boiled for 15-30 minutes in water drained to soften the seeds and autoclaved at $121^{\circ} \mathrm{C}$ in a conical flask for 30 minutes. Sterilized distilled water was added for preparation of spore suspension from the slant of the fungus growing on chickpea seed agar. Haemocytometer was used for the determination of concentration of the spore suspension. It was diluted with distilled water and adjusted to $10^{6}$ spores $/ \mathrm{ml}$. 
Adjusted volume of spore suspension was added to wet the seeds and distribution of inoculm was done by shaking the flask. This material was incubated for $7-10$ days at $20^{\circ} \mathrm{C}$. Developing pycnidia were observed on seeds and its agitation with sterilized distilled water resulted in spore suspension. This suspension was filtered through muslin cloth (Shah et al., 2015).

\section{Sowing and inoculation}

Sowing of test entries was done in plastic tunnel during last week of October in blight screening nursery at Pulses Research Institute, Faisalabad, Pakistan during 2017-2019. Each genotype was planted in single row measuring by dibbler. Highly susceptible chickpea genotype AUG-424 was planted as check after each two test entries. Artificial humidity was created by a sprinkler system for disease development. Inoculm of Ascochyta fungal suspension was equally sprayed on all genotypes during initial flowering and pod filling stages (Figure 1 and 2) as described by Singh and Reddy (1993) and practiced by Shah et al. (2015) and several others to ensure good disease development.

\section{Data recorded}

Disease rating scale 1-9 was utilized for screening of genotypes against Ascochyta blight proposed by Reddy and Singh (1984) (Table 1). Severity of blight disease was recorded on the vegetative stage by using the 1-9 rating scale as described by Toker et al. (1999). The genotypes rated 1-3 were considered to be resistant, 4 moderately resistant 5, 6 Moderately susceptible, 7 were observed susceptible and 8-9 were observed highly susceptible as given in Table 1 . Means of data were compared by $t$-test (Shah et al., 2015). Disease rating scores of each line were recorded during both years and averaged.
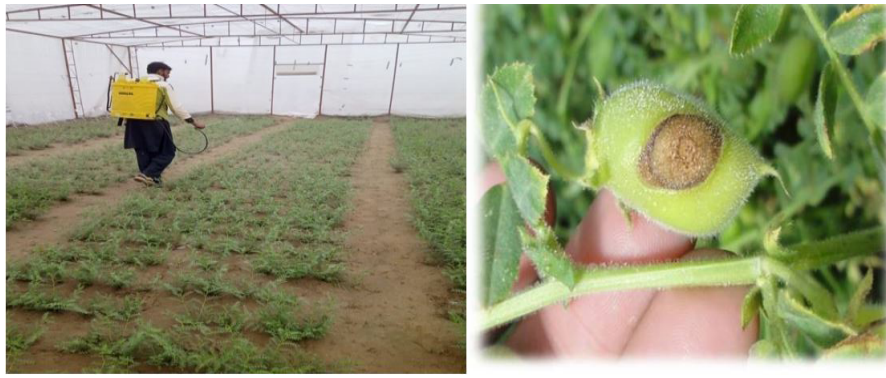

Figure 1: Spray of inoculum in Ascochyta blight screening nursery and symptoms of $A B$ during pod bearing stage.

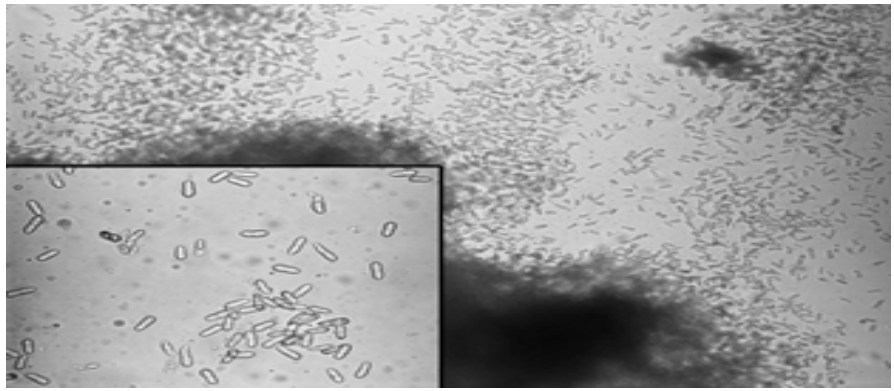

Figure 2: Spores of Ascochyta Blight under microscope.

\section{Results and Discussion}

The experimental lines were categorized according to disease rating scale (1-9). Rating of genotypes showed different host plant responses indicating a wide range of resistance among the studied elite germplasm. Data regarding the disease severity rating is evident that the genetic material was diverse in nature and the genotypes behaved differentially (Table 2). Reddy and Singh (1993) also found differential performance of genotypes regarding $\mathrm{AB}$ resistance and narrated that resistance mechanism could be controlled by single recessive or dominant gene.

\section{Table 1: Disease rating scale for Ascochyta blight (1-9).}

\begin{tabular}{|c|c|c|c|c|}
\hline $\begin{array}{l}\text { S. } \\
\text { No }\end{array}$ & Symptoms & $\begin{array}{l}\text { Infected } \\
\text { area } \%\end{array}$ & $\begin{array}{l}\text { Scale/ } \\
\text { Rating }\end{array}$ & Resistance class \\
\hline 1 & Immune, with no symptoms on plants. & 0 & 1 & With no infections \\
\hline 2 & Minute spots/lesions on the apical stem & $1-5$ & 2 & Highly Resistant (HR) \\
\hline 3 & Apical stem - slight drooping with elongating lesions & $6-10$ & 3 & Resistant (R) \\
\hline 4 & Apical stem- clear drooping with obvious lesions & $11-15$ & 4 & Moderately Resistant (MR) \\
\hline 5 & $\begin{array}{l}\text { All plant parts-Obvious lesions, slightly to moderate drying } \\
\text { with breaking branches }\end{array}$ & $16-40$ & 5 & Tolerant $(\mathrm{T})$ \\
\hline 6 & $\begin{array}{l}\text { Some plants killed while some have broken \& dry branches } \\
\text { common }\end{array}$ & $41-50$ & 6 & Moderately susceptible(MS) \\
\hline 7 & $\begin{array}{l}\text { Plants having mortality of } 25 \% \text { like lesions as in } 5 \text { with defoliat- } \\
\text { ed, broken and dry branches }\end{array}$ & $51-75$ & 7 & Susceptible (S) \\
\hline 8 & Plants having mortality of $50 \%$ like category 7 & $76-100$ & 8 & Highly susceptible (HS) \\
\hline 9 & Plants having mortality of $100 \%$ like category 7 & $100 \%$ & 9 & Highly susceptible (HS) \\
\hline
\end{tabular}

December 2021 | Volume 34 | Issue 4 | Page 776 
Table 2: Disease severity rating of chickpea advance lines during 2018-19 and 2019-20.

\begin{tabular}{|c|c|c|c|c|c|c|c|c|c|}
\hline S. No & Entries & Type & $\begin{array}{l}\text { Severity } \\
\text { mean } \pm S E\end{array}$ & $\begin{array}{l}\text { Disease Rank/ } \\
\text { class }\end{array}$ & S. No & Entries & Type & $\begin{array}{l}\text { Severity } \\
\text { mean } \pm S E\end{array}$ & $\begin{array}{l}\text { Disease } \\
\text { Rank/ class }\end{array}$ \\
\hline 1 & D-16001 & Desi & $6.2 \pm 0.7$ & MS & 31 & D-17024 & Desi & $4.2 \pm 0.3^{* *}$ & MR \\
\hline 2 & D-16003 & Desi & $6.3 \pm 1.0$ & MS & 32 & D-17025 & Desi & $7.3 \pm 0.9$ & S \\
\hline 3 & D-16004 & Desi & $6.7 \pm 0.6$ & MS & 33 & D-17026 & Desi & $6.2 \pm 0.7$ & MS \\
\hline 4 & D-16005 & Desi & $5.1 \pm 0.3$ & $\mathrm{~T}$ & 34 & D-17027 & Desi & $6.1 \pm 0.9$ & MS \\
\hline 5 & D-16006 & Desi & $7.7 \pm 0.9$ & $\mathrm{~S}$ & 35 & D-17028 & Desi & $5.2 \pm 0.3$ & $\mathrm{~T}$ \\
\hline 6 & D-16009 & Desi & $6.2 \pm 0.7$ & MS & 36 & D-17029 & Desi & $7.1 \pm 0.7$ & S \\
\hline 7 & D-16010 & Desi & $6.1 \pm 0.9$ & MS & 37 & D-17030 & Desi & $6.2 \pm 0.3$ & MS \\
\hline 8 & D-17001 & Desi & $4.1 \pm 0.6^{* *}$ & MR & 38 & D-17031 & Desi & $7.4 \pm 0.6$ & S \\
\hline 9 & D-17002 & Desi & $6.3 \pm 0.7$ & MS & 39 & D-17032 & Desi & $4.4 \pm 0.3^{* *}$ & MR \\
\hline 10 & D-17003 & Desi & $6.2 \pm 0.3$ & MS & 40 & $\mathrm{~Pb}-2008$ & Desi & $5.2 \pm 0.6$ & $\mathrm{~T}$ \\
\hline 11 & D-17004 & Desi & $6.1 \pm 0.7$ & MS & 41 & K-15012 & Kabuli & $8.1 \pm 0.3$ & HS \\
\hline 12 & D-17005 & Desi & $4.0 \pm 0.9^{* *}$ & MR & 42 & K-16025 & Kabuli & $8.4 \pm 0.7$ & HS \\
\hline 13 & D-17006 & Desi & $7.2 \pm 0.7$ & $\mathrm{~S}$ & 43 & K-16026 & Kabuli & $8.2 \pm 1.0$ & HS \\
\hline 14 & D-17007 & Desi & $7.0 \pm 0.7$ & S & 44 & K-16027 & Kabuli & $7.1 \pm 0.3$ & S \\
\hline 15 & D-17008 & Desi & $4.2 \pm 0.8^{* *}$ & MR & 45 & K-16028 & Kabuli & $8.1 \pm 0.7$ & HS \\
\hline 16 & D-17009 & Desi & $4.4 \pm 0.6^{* *}$ & MR & 46 & K-16029 & Kabuli & $8.3 \pm 0.9$ & HS \\
\hline 17 & D-17010 & Desi & $7.4 \pm 0.3$ & $\mathrm{~S}$ & 47 & K-17011 & Kabuli & $8.1 \pm 0.9$ & HS \\
\hline 18 & D-17011 & Desi & $4.1 \pm 0.7^{* *}$ & MR & 48 & K-17012 & Kabuli & $7.1 \pm 0.3$ & S \\
\hline 19 & D-17012 & Desi & $7.7 \pm 0.9$ & $\mathrm{~S}$ & 49 & K-17013 & Kabuli & $8.0 \pm 0.9$ & HS \\
\hline 20 & D-17013 & Desi & $6.2 \pm 0.7$ & MS & 50 & K-17014 & Kabuli & $7.3 \pm 0.6$ & S \\
\hline 21 & D-17014 & Desi & $6.1 \pm 0.9$ & MS & 51 & K-17021 & Kabuli & $8.2 \pm 0.7$ & HS \\
\hline 22 & D-17015 & Desi & $7.2 \pm 0.7$ & $\mathrm{~S}$ & 52 & K-17022 & Kabuli & $8.4 \pm 0.3$ & HS \\
\hline 23 & D-17016 & Desi & $7.1 \pm 0.6$ & S & 53 & K-17023 & Kabuli & $7.4 \pm 0.6$ & S \\
\hline 24 & D-17017 & Desi & $6.1 \pm 0.7$ & MS & 54 & K-17024 & Kabuli & $7.0 \pm 0.3$ & S \\
\hline 25 & D-17018 & Desi & $6.2 \pm 0.3$ & MS & 55 & K-17025 & Kabuli & $8.1 \pm 0.9$ & HS \\
\hline 26 & D-17019 & Desi & $6.2 \pm 0.7$ & MS & 56 & K-17027 & Kabuli & $7.2 \pm 0.6$ & S \\
\hline 27 & D-17020 & Desi & $7.2 \pm 0.6$ & $\mathrm{~S}$ & 57 & K-17028 & Kabuli & $8.1 \pm 0.9$ & HS \\
\hline 28 & D-17021 & Desi & $7.1 \pm 0.3$ & $\mathrm{~S}$ & 58 & K-17029 & Kabuli & $8.2 \pm 0.6$ & HS \\
\hline 29 & D-17022 & Desi & $6.2 \pm 0.3$ & MS & 59 & K-17030 & Kabuli & $8.0 \pm 0.9$ & HS \\
\hline 30 & D-17023 & Desi & $4.0 \pm 0.6^{* *}$ & MR & 60 & K-17031 & Kabuli & $7.3 \pm 0.6$ & S \\
\hline
\end{tabular}

HS: Highly susceptible; MR: Moderately resistant; MS: Moderately susceptible; S: Susceptible; SE: Standard error.

Similar findings were also observed by different researchers in Chick pea crop grown under Pakistani climate (Aslam et al., 2008; Khan et al., 2018). Data revealed that most of the investigated advance lines had high level of susceptibility to Ascochyta blight. All the genotypes were ranked for their reaction to the disease under controlled environmental conditions.

Results showed that none of the lines was resistant, 8 desi chickpea lines (D-17001, D-17005, D-17008, D-17009, D-17011, D-17023, D-17024 and D-17032) were found moderately resistant with disease severity rating of 4 . Our findings agree to the previous findings of (Collard et al., 2003; Rashid et al.,
2014; Shah et al., 2015) who also reported that desi types are more resistant to $\mathrm{AB}$ disease than kabuli types. It was also recorded that 3 entries (D-17005, D-170025 and a commercial variety Punjab-2008 were tolerant having disease severity rating of 5 . While 17 lines behaved as moderately susceptible showing disease severity rating of 6 and the rest 32 lines were categorized as susceptible and highly susceptible with disease severity rating of 7-8. (Alam et al., 2003; Chaudhry et al., 2005; Shah et al., 2015; Gayacharan et al., 2020) also reported similar kind of results. The susceptible and highly susceptible genotypes have no utility in breeding programs however the genotypes with resistant to moderately resistant response may 
be utilized for breeding program (Sahi et al., 2012; Sarwar et al., 2012; Pande et al., 2005). Based on this study, moderately resistant advance lines obtained from screening will be useful in future breeding programs for development of blight resistant chickpea cultivars.

\section{Conclusions and Recommendations}

From the present study it was concluded that no line was resistant to Ascochyta blight however eight chickpea desi lines were found moderately resistant while all other lines were susceptible to highly susceptible. Identified moderately resistant lines (D-17001, D-17005, D-17008, D-17009, D-17011, D-17023, D-17024, D-17032) may be exploited further in chickpea breeding program for development of $\mathrm{AB}$ tolerant chickpea commercial cultivars.

\section{Acknowledgments}

The author wishes to thank Head of Plant Pathology Research Institute, Faisalabad, Pakistan for supporting and facility provision for this long term field experiment.

\section{Novelty Statement}

Chickpea (Cicer arietinum L.) crop production now a days facing yield loss due to Ascochyta blight $(A B)$ even which is an important leguminous crop but in the Faisalabad area it is the first study to evaluate its loss in chickpea crop.

\section{Author's Contribution}

Javed Anwar Shah designed and collected data and Dr. Azhar Iqbal analyzed the data and Muhammad Tariq Mahmood and Dr. Muhmmad Aslam they designed this experiment. Muneer Abbas prepared the first draft of the article. Ilyas Ahmad also finalized the draft after a careful reading.

\section{Conflict of interest}

The authors have declared no conflict of interest.

\section{References}

Alam, S.S., M. Hassan, M.A.Haq, T.M. Shah, B.M. Atta and H. Syed. 2003. Screening for Ascochyta blight resistance in chickpea. Mycopath, 1:

\section{9-130.}

Alam, S.S., R.N. Strange and S.H. Qureshi. 1987. Isolation of Ascochyta rabiei and a convenient method for copious inoculum production. Mycologist. 1(1): 20.

Aslam, M., J.A. Shah, N. Hussain. A. Ghaffar, M. Abbas, M.F.H. Shah, and M. Irshad. 2020. Chickpea advanced lines screening for sources of resistance against two major diseases of Chickpea "Wilt and Blight". J. Anim. Plant Sci., 32(2): 2022. https://doi.org/10.36899/ JAPS.2022.2.0439

Aslam, M., H.K. Ahmad, M. Ayaz, E. Ahmad and M. Arshad. 2008. Effect of available soil moisture depletion levels and topping treatments on growth rate and total dry biomass in chickpea. J. Agric. Res. 26 (3): 229-243.

Atta, B.M,M.A.Haq,T.M.Shah, S.S.Alam,H.Ali, and K.P. Akhtar. 2006. Chickpea germplasm screening for resistance against ascochyta blight. Caderno de Pesquisa Ser. Bio., Santa Cruz do Sul, 18(2): 137-150.

Baite, M.S., S.C. Dubey and B. Singh. 2016. Morphological variability in the Indian isolates of Ascochyta rabiei causing blight in chickpea and evaluation of chickpea cultivars. Ind. J. Plant Protect., 44: 74-82.

Chaudhry, M.A., M. Faquir and A. Muhammad. 2005. Screening of chickpea germplasm for resistance to Ascochyta blight. J. Agric. Res., 43: 229-233.

Chongo, G., L. Buchwaldt, B.D. Gossen, G.P. Lafond, W.E. May, E.N. Johnson and T. Hogg. 2003. Foliar fungicides to manage Ascochyta blight (Ascochyta rabiei) of chickpea in Canada). Indian Dent. Assoc., 25: 135-142. https://doi. org/10.1080/07060660309507061

Collard, B.C.Y., E.C.K. Pang, P.K. Ades and P.W.J. Taylor. 2003. Preliminary investigation of QTLs associated with seedling resistance to Ascochyta blight from Cicer echinospermum, a wild relative of chickpea. Theor. Appl. Genet., 107(4): 719-729. https://doi.org/10.1007/ s00122-003-1297-X

Duzdemir, O., B. Selvi, Y. Yanar and A. Yildirimi. 2014. Sources of resistance in chickpea (Cicer arietinum L.) land races against Ascochyta rabiei causal agent of Ascochyta blight disease. Pak. J. Bot., 46(4): 1479-1483.

FAOSTAT, 2021. Food and Agriculture Organization of the United Nations. [Internet]. 
http://faostat.fao.org/site/567/default.aspx

Gan, Y.T., K.H.M. Siddique, W.J. MacLeod and

P. Jayakumar. 2006. Management options for minimizing the damage by Ascochyta blight (Ascochyta rabiei) in chickpea (Cicer arietinum L.). Field Crops Res., 97(2-3): 121-134. https:// doi.org/10.1016/j.fcr.2005.10.002

Gayacharan, U. Rani, S. Singh, A.K. Basandrai, V.K. Rathee and K. Tripathi. 2020. Identification of novel resistant sources for Ascochyta blight (Ascochyta rabiei) in chickpea. PLoS One, 15(10): e0240589. https://doi.org/10.1371/ journal.pone.0240589

Hirich, A., H. El-Omari, S.E. Jacobsen, N. Lamaddalena, A. Hamdy, R. Ragab, A. Jelloul and R. Choukr-Allah. 2014. Chickpea (Cicer arietinum L.) physiological, chemical and growth responses to irrigation with saline water. Austr. J. Crop Sci., 8(5): 646.

Ilyas, M.B., M.A. Chaudhry, N. Javed, M.U. Ghazanfar and M.A. Khan. 2007. Sources of resistance in chickpea germplasm against Ascochyta blight. Pak. J. Bot., 39(5): 1843-1847.

Islam, M., S. Mohsan, S. Ali, R. Khalid, F. Hassan, A. Mahmood and A. Subhani. 2011. Growth, nitrogen fixation and nutrient uptake by chickpea (Cicer arietinum L.) in response to phosphorus and sulfur application under rain fed conditions in Pakistan. Int. J. Agric. Biol., 13: 725-730.

Jamil, F.F., M. Sarwar, N. Sarwar, J.A. Khan, M.H. Zahid, S. Yousaf, H.M.I. Arshad and I. Haq. 2010. Genotyping with RAPD markers resolves pathotype diversity in the Ascochyta blight and Fusarium wilt pathogens of chickpea in Pakistan. Pak. J. Bot., 42: 1369-1378.

Khan,M.I,W.Arshad,M.Zeeshan,S.Ali,A.Nawaz, A. Batool and M. Fayyaz. 2018. Screening of chickpea kabuli (Cicer arietinum L.) germplasm against Ascochyta blight. J. Biodiver. Environ. Sci., 12(2): 128-132.

Khan, M.I., W. Arshad, M. Zeeshan, S. Ali, A. Nawaz, A. Batool and M. Fayyaz. 2018. Screening of chickpea kabuli (Cicer arietinum L.) germplasm against Ascochyta blight (Ascochyta rabiei). J. Biodiver. Environ. Sci., 12(2): 128-132.

Mahmood, M.T., M. Ahmad and I. Ali. 2019. Chickpea blight: former efforts on pathogenicity, resistant germplasm and disease management. Gomal Univ. J. Res. 35: 1-10.
Malhotra, R.S., M. Baum, S.M. Udupa, B. Bayaa,

S. Kabbabe, G. Khalaf. 2003. Ascochyta blight resistance in chickpea: Present status and future prospects. International Chickpea Conference, Raipur, India, January 2003

Malik, S.R., M. Saleem, U. Iqbal, M.A. Zahid, A. Bakhah and S.M. Iqbal. 2011. Genetic analysis of physiochemical traits in chickpea (Cicer arietinum L.) seeds. Int. J. Agric. Biol., 13: 1033-1036.

Megersa, T., T. Losenge and O. Chris. 2017. The Survey of Chickpea (Cicer arietinum L) Ascochyta blight (Ascochyta rabiei Pass.) Disease Status in Production Regions of Ethiopia. Plant, 5(1): 23-30. https://doi.org/10.11648/j. plant.20170501.15

Pande, S., K.H.M, Siddique, G.K. Kishore, B. Bayaa, P.M. Gaur, C.L.L. Gowda, T.W. Bretag and J.H. Crouch. 2005. Ascochyta blight of chickpea (Cicer arietinum L.): A review of biology, pathogenicity, and disease management. Aust.J. Agric. Res., 56(4): 317-332. https://doi. org/10.1071/AR04143

Pande, S.K., H.M.S. Siddique, G.K. Kishore, B. Bayaa, P.M. Gaur, C.L.I. Gowda, T.W. Bretag, and J.H. Crouch. 2005. Ascochyta blight of chickpea (Cicer arietinum L): A review of biology, pathogenicity, and disease management. Austr. J. Agric. Res., 56(4): 317332. https://doi.org/10.1071/AR04143

Rashid,A.,M.U.Younas,M.Ehetisham-ul-Haq,M. Farooq, I.H. Waris, E. Perveez and M. Ahmad. 2014. Screening of chickpea (Cicer arietinum L.) varieties against Ascochyta blight and its management through biopesticides. Archives of Phytopathology and Plant Protection. 47(8): 938-943.

Reddy, M.V. and K.B. Singh. 1984. Evaluation of a world collection of chickpea germ plasm accessions for resistance to Ascochyta blight. Plant Dis. 68(10): 900-901.

Reddy, M.V. and K.B. Singh. 1993. Producing resistance to Ascochyta blight in chickpea. Plant Dis., 77: 231-233. https://doi.org/10.1094/ PD-77-0231

Reddy, M.V. and Y.L. Nene. 1979. A case for induced mutation in chickpea for Ascochyta blight resistance.

Rubiales, D., S. Fondevilla, W. Chen and J. Davidson. 2018. Editorial: Advances in Ascochyta Research. Front. Plant Sci., 9: 22. 
https://doi.org/10.3389/fpls.2018.00022

Sahi, M.S. Talib, M. Burhan, T. Iqbal and N. Sarwar, 2012. Screening of chickpea breeding material and varieties / elite lines against blight. Ascochyta rabiei. J. Agric. Res., 50 (4).

Sarwar, N., K.P. Akhtar, T.M. Shah and B.M. Atta. 2012. Evaluation of chickpea advance genotypes against blight and wilt diseases under field conditions. Int. J. Agric. Biol., 14: 993-996.

Shah, T.M., M. Hassan, M.A. Haq, B.M. Atta, S.S. Alam and H. Ali. 2005. Evaluation of Cicer species for resistance to Ascochyta blight. Pak. J. Bot., 37: 431-438.

Shah, T.M., M. Imran, B.M. Atta, M. Shafiq, M. Aslam and K. Hussain. 2015. Screening of chickpea advanced lines for sources of resistance against blight and wilt two major diseases of chickpea. Pak. J. Bot., 47(6): 2443-2448.

Singh, K.B. and M.V. Reddy. 1993. Resistance to six races of Ascochyta rabiei in the world germplasm collection of Chickpea. Crop Sci., 33: 186-189. https://doi.org/10.2135/ cropsci1993.0011183X003300010033x

Tekeoglu, M., D.K. Santra, W.J. Kaiser and F.J. Muehlbauer. 2000. Ascochyta blight resistance inheritance in three chickpea recombinant inbred line populations. Crop Sci., 40(5): 1251-1256. https://doi.org/10.2135/ cropsci2000.4051251x

Toker, C., B. Uzun and M.I. Cagirgan. 1999. Screening and selection for resistance to Ascochyta blight [Ascochyta rabiei (Pass) Labr.] of chickpea (Cicer arietinum L.) under field conditions. J. Turk. Phytopathol., 28: 101-110. 